\title{
Chloromonilinic Acids A and B, Novel Catabolites of the Growth Self-inhibitor Chloromonilicin Isolated from Monilinia fructicola
}

\author{
Takeshi Sassa, Kazuo Horiguchi and Yoshikatsu Suzuki* \\ Department of Agricultural Chemistry, Yamagata University, \\ Tsuruoka, Yamagata 997, Japan \\ * The Institute of Physical and Chemical Research, \\ Wako, Saitama 351, Japan
}

Received December 5, 1988

\begin{abstract}
Chloromonilinic acids A and B were newly isolated from a culture filtrate of $M$. fructicola accumulating chloromonilicin in the mycelium, and their structures were elucidated on the basis of spectroscopic evidence. The unusual catabolic route of chloromonilicin is discussed.
\end{abstract}

Chloromonilicin (I) has been isolated as a growth self-inhibitor from cherry rot fungus, Monilinia fructicola, and its novel structure with a $\beta$-chloro- $\alpha, \beta, \gamma, \delta$-unsaturated sevenmembered lactone ring has been elucidated on the basis of chemical and spectroscopic evidence. ${ }^{1)}$ In the course of a biosynthetic study of $\mathbf{I}^{2)}$ we found two strongly acidic metabolites in the culture broth of this fungus accumulating $I$ in its mycelia. These metabolites containing a chlorine atom were named chloromonilinic acids $\mathrm{A}$ (III) and B (IV). The chlorine atom in I was readily eliminated as hydrogen chloride by mild alkaline methanolysis with the formation of a biologically inactive compound II (Fig. 1). ${ }^{1)}$ On the other hand, III and IV showed a complete or almost complete lack of biological activity. These observations seemed to present an interesting clue to investigate the catabolic mechanism and structure-activity relationship of $I$. The present paper reports the isolation and structural de- termination of III and IV. The fungal transformation of bromomonilicin ( $\mathbf{V}$, a homologue of I) to bromomonilinic acids A (VI) and B (VII), that was in parallel with that of $I$, was also examined in this fungus.

$M$. fructicola was grown in a culture medium containing $2 \%$ commercial sugar and $2 \%$ malt extract in 500-ml Sakaguchi flasks at $24^{\circ} \mathrm{C}$ for 14 days on a reciprocal shaker. Combined EtOAc extracts of the broth filtrate (initially $\mathrm{pH} 4.2$ and then adjusted to $\mathrm{pH} 3$ ) were chromatographed by a stepwise elution over silica gel with an $n$-hexane-EtOAc mixture containing $1 \% \mathrm{AcOH}$ to give the strongly acidic fractions $5(n$-hexane-EtOAc $=3: 1)$ and 8 ( $n$-hexane-EtOAc $=3: 2 \sim 2: 3$ ). Rechromatography of fraction 8 over silica gel with $18: 1$ $\mathrm{CHCl}_{3}$-2-propanol containing $1 \% \mathrm{AcOH}$ and its subsequent purification by preparative silica gel TLC, developing with EtOAc containing $0.5 \% \mathrm{HCOOH}$, afforded III as pale yellow needles; mp $181.5 \sim 182^{\circ} \mathrm{C}$. Frac-

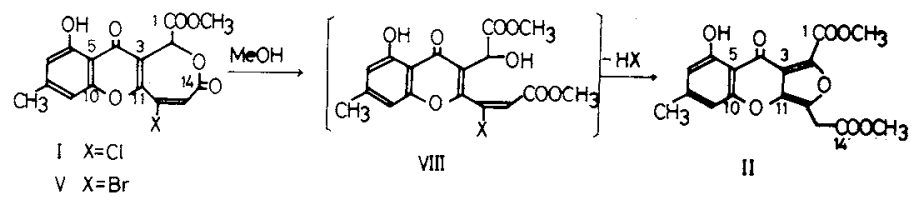

Fig. 1. Structures of Chloromonilicin (I) and Bromomonilicin (V), and of their Methanolysis Products (II and VIII). 


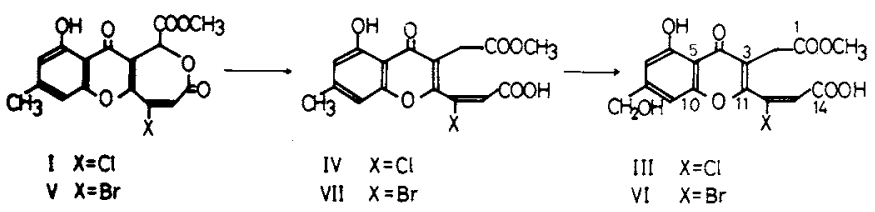

Fig. 2. Catabolic Route of Halomonilicins (I and V) to Halomonilinic Acids A (III and VI) and B (IV and VII), and Structures of Chloromonilinic Acids A (III) and B (IV), and of Bromomonilinic Acids A (VI) and B (VII).

tion 5 was purified by preparative silica gel TLC, developing with $2: 1$ benzene-acetone containing $0.5 \% \mathrm{HCOOH}$, to afford $\mathbf{I V}$ as pale yellow prisms; $\mathrm{mp} 171.5 \sim 172.5^{\circ} \mathrm{C}$.

III gave a pale violet color with alcoholic ferric chloride. Its molecular formula, $\mathrm{C}_{16} \mathrm{H}_{13} \mathrm{O}_{8} \mathrm{Cl}$, was determined by highresolution mass spectrometry. The NMR spectrum of III showed the presence of a hydrogen-bonded phenolic hydroxyl (12.5 ppm) and a methoxy group (3.65 ppm). III gave a methyl ester on treatment with $\mathrm{MeOH}$ -conc. $\mathrm{H}_{2} \mathrm{SO}_{4}$. It showed a strong IR absorption at $1731 \mathrm{~cm}^{-1}$ and two NMR signals of a three-proton singlet at 3.70 and $3.63 \mathrm{ppm}$, indicating the presence of two carbomethoxy groups in III methyl ester. The methyl ester gave a diacetate having no hydroxyl IR absorptions. Its NMR spectrum showed a twoproton singlet with an acetylation shift at $5.16 \mathrm{ppm}$, together with two acetoxyl signals at 2.39 and $2.11 \mathrm{ppm}$. These observations indicated that III possessed a carboxyl and a carbomethoxy group, as well as a hydrogenbonded phenolic hydroxyl and a hydroxymethyl group in the molecule.

The NMDR spectra of III revealed clearly the presence of a pair of meta-coupled protons ( 7.07 and $6.87 \mathrm{ppm}, J=1.5 \mathrm{~Hz}$ ) on a benzene nucleus and a hydroxymethyl group $(4.75 \mathrm{ppm})$ allylically coupled to each of the meta-coupled protons. The meta-coupled protons were shifted downfield (7.35 and 7.00 $\mathrm{ppm}$ ) in the NMR spectrum of the diacetate of III methyl ester. These NMR data suggested the presence of a 2-acyl-3-alkoxy-5-(hydroxymethyl)-phenol moiety in III. ${ }^{3)}$

A careful comparison of the characteristic UV spectrum of III with those of the de- rivatives of I obtained so far reveals that III contained a UV chromophore identical with that of VIII, a lactone-ring cleaved intermediate from the alkaline methanolysis of I (Fig. 1). ${ }^{1)}$ The ${ }^{13} \mathrm{C}-\mathrm{NMR}$ spectra (COM, INEPT, NOE and LSPD) of III methyl ester confirmed the structure of this UV chromophore, and further extended it to a 3(carbomethoxymethyl)chromone substituted at 2 by a 2-carbomethoxy-1-chlorovinyl group. The structure of III methyl ester was justified by comparing the ${ }^{13} \mathrm{C}-\mathrm{NMR}$ chemical shifts with those of I; 181.5 (C-4), 169.7 (C-1), 162.2 (C-14), 160.3 (C-6), 157.5 (C-11), 156.2 (C-10), 150.8 (C-8), 137.4 (C-12), 126.2 (C-13), 115.0 (C-3), 109.0 (C-5), 108.8 (C-9), 104.3 (C-7), $63.9\left(\mathrm{CH}_{2} \mathrm{OH}\right), 52.3\left(\mathrm{OCH}_{3}\right), 52.1\left(\mathrm{OCH}_{3}\right)$ and $29.9 \mathrm{ppm}(\mathrm{C}-2)$. The ${ }^{13} \mathrm{C}-\left[{ }^{1} \mathrm{H}\right]$ long-range selective proton decoupling (LSPD) analysis using an improved method of SPT difference spectrum $^{4)}$ clearly indicated heteronuclear longrange couplings between the methylene protons at $\mathrm{C}-2(3.48 \mathrm{ppm})$ and $\mathrm{C}-4$ (181.5), C-1 (169.7), C-11 (157.5) and C-3 (115.0 ppm), and between the olefinic proton at C-13 $(6.57 \mathrm{ppm})$ and $\mathrm{C}-11$ (157.5) and $\mathrm{C}-12$ (137.4 ppm). ${ }^{5}$ Finally the ester function of $\mathrm{C}-1$ in III was revealed by LSPD experiments and its SPT difference spectrometry on III in dioxane- $d_{8}$; long-range couplings were observed between the methoxyl group (3.61 ppm) and C-1 $(170.9 \mathrm{ppm})$, and between the methylene protons at C-2 (3.46 ppm) and C-4 (183.2), C-1 (170.9), C-11 (159.2) and C-3 (117.1 ppm). Therefore, the structure of III was elucidated to be that shown in III (Fig. 2). The close similarity of the ${ }^{1} \mathrm{H}$ - and ${ }^{13} \mathrm{C}-\mathrm{NMR}$ data for the $\mathrm{C}-11 \sim \mathrm{C}-14$ moiety in III methyl ester to those in I suggested that the double bond of III 
had the same $E$ configuration as that of $\mathbf{I}$.

IV gave the same color as that of III with alcoholic ferric chloride. The UV spectrum of IV was superimposable on that of III, and its IR spectrum was similar to that of III. The NMR spectrum of IV also showed many signals corresponding to those of III, a threeproton singlet at $2.42 \mathrm{ppm}$ instead of the twoproton singlet at $4.75 \mathrm{ppm}$ in III. These observations suggested that IV was a deoxy derivative of III. This was confirmed from the ${ }^{13} \mathrm{C}-\mathrm{NMR}$ data for IV; 183.1 (C-4), 171.0 (C1), 164.4 (C-14), 162.0 (C-6), 159.1 (C-11), 157.8 (C-10), 149.6 (C-8), 138.0 (C-12), 129.4 (C-13), 117.0 (C-3), 113.7 (C-9), 109.7 (C-5), $108.8(\mathrm{C}-7), 53.0\left(\mathrm{OCH}_{3}\right), 31.3(\mathrm{C}-2)$ and $23.0 \mathrm{ppm}\left(\mathrm{CCH}_{3}\right)$. The very weak peak of the fragment ion $\mathrm{M}^{+}-\mathrm{COOCH}_{3}[\mathrm{~m} / z 295$ and 293 (chlorine-containing ions)] in the mass spectrum of IV suggested that the ester function was located at C-1 in analogy with III. Thus, the structure of IV was assigned to be that shown in IV (Fig. 2), which is considered as
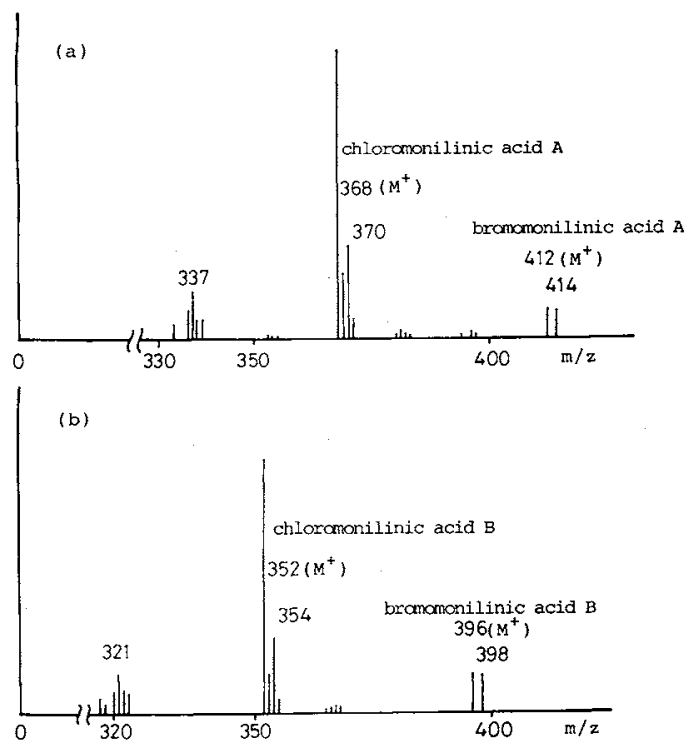

Fig. 3. MS Data for the Fractions of Chloromonilinic Acids A (III) and B (IV) Obtained by the Feeding Experiments.

(a): The fraction of III from the additional 5-day incubation.

(b): The fraction of IV from the additional 3-day incubation (III was not found in the culture broth by TLC). being a biosynthetic precursor of III.

The catabolic conversion of bromomonilicin $(\mathbf{V}$, a homologue of $\mathbf{I})$ produced $^{6)}$ in the presence of the bromine ion was also investigated by feeding $\mathbf{V}$ and examining the products by mass analysis. $\mathbf{V}$ was fed to the fermentation broth 7 days after inoculation. After an additional 3 or 5 days, the broth filtrate (initially $\mathrm{pH} 4.3$ and then adjusted to $\mathrm{pH} 3$ ) was extracted with EtOAc. The fractions of III and/or IV obtained from the extract by preparative silica gel TLC were subjected to mass analyses. The molecular ions of the bromine-containing catabolites VI and VII (Fig. 2) were clearly detected in the mass spectra of the fractions corresponding to III and IV, respectively (Fig. $3)$. In addition, the incorporation of deuterated moniliphenone, ${ }^{1,7)}$ a biosynthetic intermediate of $\mathbf{I}$, in IV was observed by mass spectrometry.

III showed no inhibitory activity at less than $500 \mu \mathrm{g} /$ disc in a growth self-inhibiting assay, ${ }^{8)}$ while the growth self-inhibiting activity of IV (MID ca. $250 \mu \mathrm{g} / \mathrm{disc}$ ) was about onehundredth of that of I. III also showed no antifungal activity against several fungi by the agar dilution method.

The combined results indicate that, for both I and $\mathbf{V}$, the fungus reductively cleaved the 7 membered lactone ring to give IV (or VII), and that the product was oxidized at the methyl group on the benzene ring to give III (or VI). The catabolic route of $\mathbf{I}$ to IV was not the usual hydrolytic cleavage of the lactone ring, but an unusual reductive cleavage. This biodegradation makes an interesting contrast with the ease of chemical dehydrochlorination by mild alkaline methanolysis and, further, is considered to be significant as one of the catabolic mechanisms for biologically active lactones.

\section{Experimental}

Melting points ( $\mathrm{mp}$ ) are uncorrected. The following spectroscopic instruments were used: MS, ZAB-SE (HRMS) and JEOL JMS-Q10A; UV, Hitachi 124; IR, Jasco UVIDEC-510; 'H-NMR, Hitachi R-24 (60 MHz) and JEOL FX-90Q (90 MHz); ${ }^{13} \mathrm{C}-\mathrm{NMR}$, JEOL FX-90Q (22.5 MHz). BW-820 MH and CQ-3 silica gel (Fuji 
Division Chemical Company) were used for column chromatography, and $60 \mathrm{~F}_{254}$ s silica gel TLC plates (Merck, $0.5 \mathrm{~mm}$ thickness) for preparative TLC.

Isolation of chloromonilinic acids $A$ (III) and B (IV). The spore suspension of $M$. fructicola was inoculated into a $100 \mathrm{ml}$ culture medium containing $2 \%$ commercial sugar and $2 \%$ malt extract in a $500-\mathrm{ml}$ Sakaguchi flask, before the flasks were incubated at $24^{\circ} \mathrm{C}$ for 14 days on a reciprocal shaker. The broth filtrate obtained ( 5 l; initially $\mathrm{pH} 4.2$ and then adjusted to $\mathrm{pH} 3$ ) was saturated with $\mathrm{NaCl}$ and then extracted 3 times with EtOAc. The combined EtOAc extracts ( $1.43 \mathrm{~g}$ ) were chromatographed by a stepwise elution over $\mathrm{BW}-820 \mathrm{MH}$ silica gel with an $n$ hexane-EtOAc mixture containing $1 \% \mathrm{AcOH}$ to give the strongly acidic fractions $5(n$-hexane-EtOAc $=3: 1 ; 67 \mathrm{mg})$ and 8 ( $n$-hexane-EtOAc $=3: 2 \sim 2: 3 ; 330 \mathrm{mg}$ ). Rechromatography of fraction 8 over CQ-3 silica gel with $18: 1$ $\mathrm{CHCl}_{3}-2$-propanol containing $1 \% \mathrm{AcOH}$ and its subsequent purification by preparative silica gel TLC, developing with EtOAc containing $0.5 \% \mathrm{HCOOH}$, afforded III (155 mg); its recrystallization with EtOAc-benzene gave pale yellow needles, mp $181.5 \sim 182^{\circ}$. Fraction 5 was purified by preparative silica gel TLC, developing with $2: 1$ benzene-acetone containing $0.5 \% \mathrm{HCOOH}$, to afford IV $(39 \mathrm{mg}$ ); its recrystallization with acetone-benzene gave pale yellow needles, $\mathrm{mp} 171.5 \sim 172.5^{\circ} \mathrm{C}$. Chloromonilicin (63 mg) was also isolated from the EtOAc extracts just mentioned, and $307 \mathrm{mg}$, from the mycelial extracts.

III. EI-MS $m / z: 368\left(\mathrm{M}^{+}\right), 337,323,309$ and $292\left({ }^{35} \mathrm{Cl}\right.$ containing ions), 333, 263, 257, 229, 166 and 121; HREIMS: $m / z 368.0299380\left(\mathrm{M}^{+}\right.$, calcd. for $\mathrm{C}_{16} \mathrm{H}_{13} \mathrm{O}_{7} \mathrm{Cl}$ : 368.0298957); UV $\lambda_{\text {max }}(\mathrm{MeOH}) \mathrm{nm}(\varepsilon): 331$ (3,900), 260 (sh. 16,000) and $244(18,000)$; IR $v_{\max }(\mathrm{KBr}) \mathrm{cm}^{-1}: 3420$, $2700,2590,1718$ (br.), 1652, 1635, 1603, 1437, 1327, 1163, $1061,946,840,745$ and $660 ;{ }^{1} \mathrm{H}-\mathrm{NMR} \delta$ (acetone- $\left.d_{6}\right): 12.5$ $(1 \mathrm{H}, \mathrm{OH}), 7.07(1 \mathrm{H}, \mathrm{m}), 6.87(1 \mathrm{H}, \mathrm{m}), 6.78(1 \mathrm{H}, \mathrm{s}), 4.75$ $\left(2 \mathrm{H}\right.$, br. s), $3.65(3 \mathrm{H}, \mathrm{s})$ and $3.58(2 \mathrm{H}, \mathrm{s}),{ }^{13} \mathrm{C}-\mathrm{NMR} \delta$ (dioxane- $d_{8}$ ): $183.1(\mathrm{~s}), 170.9(\mathrm{~s}), 164.3(\mathrm{~s}), 162.2(\mathrm{~s}), 159.2$ $(\mathrm{s}), 158.0(\mathrm{~s}), 154.1(\mathrm{~s}), 138.1(\mathrm{~s}), 129.3(\mathrm{~d}), 117.1(\mathrm{~s}), 110.5$ (s), $110.1(\mathrm{~d}), 105.5(\mathrm{~d}), 64.8(\mathrm{t}), 53.0(\mathrm{q})$ and $31.3(\mathrm{t}) . \mathbf{I V}$. EI-MS $m / z: 352,321,307,293$ and $276\left({ }^{35} \mathrm{Cl}\right.$-containing ions), $317,248,213,185,151$ and 123 ; UV $\lambda_{\max }$ $(\mathrm{MeOH}) \mathrm{nm}(\varepsilon): 331(3,900), 260$ (sh. 16,000) and 244 $(18,000)$; IR $v_{\max }(\mathrm{KBr}) \mathrm{cm}^{-1}: 2800 \sim 2400$ (br.), 1738, $1703,1657,1601,1435,1344,1291,1163,1083,1000,842$ and $733 ;{ }^{1} \mathrm{H}-\mathrm{NMR} \delta$ (acetone- $d_{6}$ ): $12.6 \sim 12.1$ and $8.6 \sim 8.0$ (each $1 \mathrm{H}$, br. $\mathrm{OH}), 6.86(1 \mathrm{H}, \mathrm{m}), 6.75(1 \mathrm{H}, \mathrm{s}), 6.70(1 \mathrm{H}$, $\mathrm{m}), 3.63(3 \mathrm{H}, \mathrm{s}), 3.50(2 \mathrm{H}, \mathrm{s})$ and $2.42(3 \mathrm{H}, \mathrm{s}) ;{ }^{13} \mathrm{C}-\mathrm{NMR}$ $\delta$ (dioxane- $\left.d_{8}\right)$ : see the text.

Chloromonilinic acid A methyl ester (III methyl ester). III was methylated with $\mathrm{MeOH}$ in the presence of a catalytic amount of conc. $\mathrm{H}_{2} \mathrm{SO}_{4}$ at $55^{\circ} \mathrm{C}$ for $3 \mathrm{hr}$. The III methyl ester obtained was purified by preparative silica gel TLC, developing with $18: 1 \mathrm{CHCl}_{3}-2$-propanol, as a viscous oily substance. EI-MS $m / z: 382\left(\mathrm{M}^{+},{ }^{35} \mathrm{Cl}-\right.$ containing ion) the fragment ion of $\mathrm{M}^{+}-\mathrm{COOCH}_{3}(\mathrm{~m} / \mathrm{z}$ 325 and 323 ) being observed as one of the most abundant peaks; UV $\hat{\lambda}_{\max }(\mathrm{MeOH}) \mathrm{nm}(\varepsilon): 331$ (3,700), 261 (sh. $16,000)$ and $242(20,000)$; IR $v_{\max }\left(\mathrm{CHCl}_{3}\right) \mathrm{cm}^{-1} 3600$, $3600 \sim 3200$ (br.), 1731 (br.), 1660 and 1611 ; ${ }^{1} \mathrm{H}-\mathrm{NMR} \delta$ $\left(\mathrm{CDCl}_{3}\right): 12.1(1 \mathrm{H}, \mathrm{OH}), 6.93(1 \mathrm{H}, \mathrm{m}), 6.76(1 \mathrm{H}, \mathrm{m}), 6.57$ $(1 \mathrm{H}, \mathrm{s}), 4.69(2 \mathrm{H}, \mathrm{s}), 3.70(3 \mathrm{H}, \mathrm{s}), 3.63(3 \mathrm{H}, \mathrm{s}), 3.48(2 \mathrm{H}, \mathrm{s})$ and $2.6(1 \mathrm{H}$, br. $\mathrm{OH}) ;{ }^{13} \mathrm{C}-\mathrm{NMR} \delta\left(\mathrm{CDCl}_{3}\right)$ : see the text.

Diacetate of chloromonilinic acid A methyl ester (diacetate of III methyl ester). III methyl ester was acetylated with acetic anhydride in pyridine at $25^{\circ} \mathrm{C}$ overnight. The diacetate of III methyl ester was purified by preparative silica gel TLC, developing with $7: 1$ benzene-acetone, and obtained as crystals having $\mathrm{mp} 148 \sim 148.5^{\circ} \mathrm{C}$ (benzene). EI-MS $m / z: 466\left(\mathrm{M}^{+}\right)$and $424\left({ }^{35} \mathrm{Cl}\right.$-containing ions); UV $\lambda_{\max }(\mathrm{MeOH}) \mathrm{nm}(\varepsilon): 307(7,700)$ and $230(27,000)$; IR $v_{\max }$ $\left(\mathrm{CHCl}_{3}\right) \mathrm{cm}^{-1}: 1781,1740$ (br.), 1724 and $1646 ;{ }^{1} \mathrm{H}-\mathrm{NMR}$ $\delta\left(\mathrm{CDCl}_{3}\right): 7.35(1 \mathrm{H}, \mathrm{m}), 7.00(1 \mathrm{H}, \mathrm{m}), 6.53(1 \mathrm{H}, \mathrm{s}), 5.16$ $(2 \mathrm{H}, \mathrm{s}), 3.63(6 \mathrm{H}, \mathrm{s}), 3.43(3 \mathrm{H}, \mathrm{s}), 2.39(3 \mathrm{H}, \mathrm{s})$ and $2.11(3 \mathrm{H}$, s).

Fungal transformation of bromomonilicin (V) to bromomonilinic acids $A(\mathbf{V I})$ and $B(\mathbf{V I I})$. The spore suspension of $M$. fructicola was inoculated into a $100 \mathrm{ml}$ culture medium containing $2 \%$ commercial sugar and $1 \%$ malt extract in a 500-ml Sakaguchi flask, before the flask was incubated at $24^{\circ} \mathrm{C}$ for 7 days on a reciprocal shaker. $V(2 \mathrm{mg}$ in $0.04 \mathrm{ml}$ of $\mathrm{DMSO} / 0.1 \mathrm{ml}$ of $\mathrm{EtOH}$ ) was then fed to the fermentation broth. After an additional 3 or 5 days, the broth was filtered, and the filtrate (initially $\mathrm{pH} 4.3$ and then adjusted to $\mathrm{pH}$ 3) was extracted with EtOAc. The EtOAc extract obtained was subjected to preparative silica gel TLC, developing with $9: 2 \mathrm{CHCl}_{3}$-2-propanol containing $1 \%$ AcOH for the purification of III (and VI) and with $5: 1$ benzene-acetone containing $1 \%$ AcOH for IV (and VII). III (and VI) and IV (and VII) were analyzed by mass spectrometry, these MS data being shown in Fig. 3.

Incorporation of moniliphenone- $d_{5}$ into chloromonilinic acid $B(\mathbf{I V})$. Feeding experiments with moniliphenone- $d_{5}$ were carried out in a similar manner to those of bromomonilicin (V). IV (and deuterated IV) were extracted from the broth filtrate obtained from the 3-day incubation and purified by preparative silica gel TLC. The presence of deuterated IVs, i.e., IV- $d_{5}$ and $\mathbf{I V}-d_{4},{ }^{7}$ ) was confirmed by EI-MS data for purified IV (and deuterated IV); $m / z 352$ $\left[\mathrm{M}^{+}\right.$of $\mathbf{I V -}{ }^{35} \mathrm{Cl}, 100$ (rel. intensity)], 353 (17), 354 (34), $355(8), 356(\mathrm{M}+4,8), 357(\mathrm{M}+5,14), 358(6), 359(6)$ and 360 (2). EI-MS data for an authentic specimen of IV: $\mathrm{m} / \mathrm{z}$ $352\left[\mathrm{M}^{+}\right.$of $\mathbf{I V -}{ }^{35} \mathrm{Cl}, 100$ (rel. intensity)], 353 (20), 354 (39), 355 (7) and $356(1)$.

Acknowledgments. The authors thank Mr. N. Shigematsu in the Exploratory Research Laboratories of Fujisawa Pharmaceutical Co., Ltd. for HR-MS measurements, and Dr. K. Tsuji for his advice on manuscript 
preparation. This work was supported in part by a Grantin-Aid for Scientific Research from the Ministry of Education, Science and Culture of Japan.

\section{References and Notes}

1) T. Sassa, H. Kachi, M. Nukina and Y. Suzuki, J. Antibiot., 38, 439 (1985).

2) H. Kachi and T. Sassa, Agric. Biol. Chem., 50, 1669 (1986).

3) T. Hamasaki, Y. Sato and Y. Hatsuda, Agric. Biol. Chem., 39, 2341 (1975).
4) J. Uzawa and T. Shibata, Abstracts of Papers, 22nd Symposium on NMR (Japan), Kyoto, 1983, pp. $18 \sim 21$.

5) Heteronuclear long-range coupling between the olefinic proton at $6.89 \mathrm{ppm}$ and $\mathrm{C}-14$ at $161.5 \mathrm{ppm}$ was also not observed in the ${ }^{13} \mathrm{C}-\mathrm{NMR}$ spectra of $\mathbf{I}$.

6) H. Kachi, H. Hattori and T. Sassa, J. Antibiot., 39, 164 (1986).

7) The preparation of moniliphenone- $d_{5}$ and its incorporation into 4-chloropinselin and chloromonilicin will be reported in detail later.

8) T. Sassa and M. Nukina, Agric. Biol. Chem.. 48, 1923 (1984). 